\title{
Acceptance and use of e-learning systems: the case of teachers in technology institutes of Ethiopian Universities
}

\author{
Abinew Ali Ayele* and Worku Kelemework Birhanie
}

\author{
${ }^{*}$ Correspondence: \\ abinewaliayele@gmail.com \\ Faculty of Computing, Bahir \\ Dar Institute of Technology, \\ Bahir Dar University, Bahir \\ Dar, Ethiopia
}

\begin{abstract}
The aim of this study was to empirically examine e-learning acceptance and use in technology institutes of Ethiopian public universities. Samples of 400 university teachers were selected using simple random sampling technique. Structural equation modeling (SEM) analysis technique using SamrtPls tool has been used. The acceptance and use of e-learning systems have been evaluated and determinants were identified. Perceived ease of use and perceived usefulness were found to be significant determinants of behavioral intention to use e-learning systems. Behavioral intention, user training and management support were found to be major factors for actual usage of e-learning systems. Among the organizational factors, management support and user training have $56.6 \%$ contribution jointly and 30.7 and $25.9 \%$ contributions independently for the actual usage of e-learning systems. On the other hand, the impact of incentive on the actual usage of e-learning systems was found to be insignificant.
\end{abstract}

Keywords: E-learning, Perceived usefulness, Perceived ease of use, Management support, Training, Incentive

\section{Introduction}

E-learning can be defined as learning conducted via electronic media, typically on the Internet. Arkorful and Abaidoo (2015), citing the (European Commission 2001), describes e-learning as the use of Internet and new multimedia technologies to improve the quality of learning by easing access to facilities and services. Moreover, e-learning can also enhance the collaborations among learners, educators, and administrators.

The dramatic advancements of information and communication technologies have changed people's day-to-day operations in all sectors of the economy. The change is also reflected in the teaching learning activities of higher education institutions all over the world. The traditional face-to-face course delivery system needs to be supplemented with flexible e-learning technologies. Accordingly, e-learning enables institutions to have easier access for experienced professors to share with university instructors and to deliver a course across universities. More importantly, it has a significant contribution for those institutions that have scarcity of resources, shortage of well-trained, and experienced manpower. Moreover, e-learning enhances the teaching learning process and allows students to learn at their own pace and convenient time.

(c) The Author(s) 2018. This article is distributed under the terms of the Creative Commons Attribution 4.0 International License (http://creativecommons.org/licenses/by/4.0/), which permits unrestricted use, distribution, and reproduction in any medium, provided you give appropriate credit to the original author(s) and the source, provide a link to the Creative Commons license, and indicate if changes were made. 


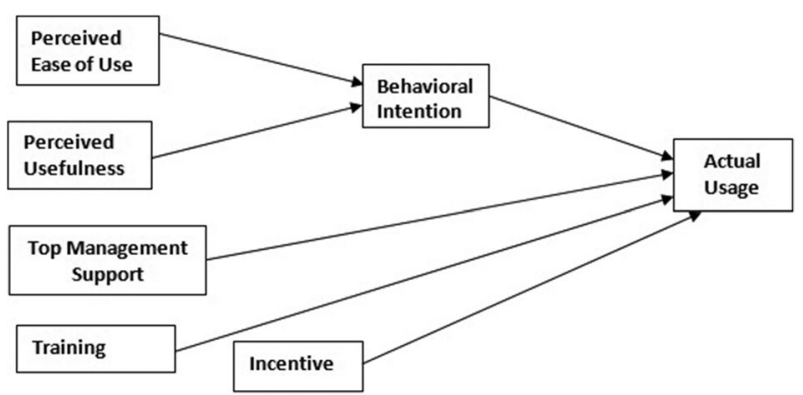

Fig. 1 Proposed research model

The ministry of education of Ethiopia has planned to increase the current enrollment rate by $35 \%$ by 2020 in achieving the second growth and transformation plan. To that end, well-trained and experienced human resource, especially in technology and engineering fields, has been identified as the major challenge (Ethiopian Ministry of Education 2015). Hence, adopting and implementing e-learning technologies in the curricula of various courses to support the traditional course delivery system will have paramount importance. This study has empirically investigated the main determinants of e-learning acceptance and use in technology institutes of Ethiopian public Universities.

\section{Theoretical background}

Researchers have identified various technology adoption determinants and proposed various adoption models. The Theory of Reasoned Action (TRA), proposed by Ajzen and Fishbein (1980) showed that the main determinant to accept and use new technologies is the persons' behavioral intent. The attitude to adopt a new technology is also determined by users' perception about the expected consequences of performing a behavior and the assessment of those consequences. Moreover, the strength of a person's intent determines the actual performance of the expected behavior. Accordingly, the main concern of this model is to identify the underlying factors of the formation and change of attitude and behavioral intent (Fig. 1).

Davis (1989) has also developed and proposed a new technology acceptance model (TAM). The model describes that the users' behavioral intention to accept and actually use a certain technology is determined by two main constructs: perceived usefulness and perceived ease of use. Perceived ease of use, perceived usefulness, and attitude showed significant contribution on behavioral intention to adopt new technologies (Alharbi and Drew 2014; Mbengo 2014).

Another important factor that significantly affects adoption of new technologies is the organizational factors. Among the organizational factors management support, user training and incentives have been found to be crucial determinants of new technology adoption. Incentive, like promotion, financial benefits as well as work load and time reduction, is an important motivating factor for employees to adopt and practice a new technology. Training helps employees to adopt a new technology by equipping employees with the knowledge and skills required to use a new technology effectively and efficiently (Talukder and Quazi 2010). Managerial support, which is a driving force 
for adopting new technology by employees, includes the provision of financial and technical assistance as well as allocating the time required to learn and understand a new technology (Talukder and Quazi 2010; Al-Mamary et al. 2014; Maina and Nzuki 2015; Al Haderi 2014).

Therefore, our study has proposed organizational factors as determinant constructs on the original TAM model. Incentive, user training as well as support and commitment of the management to implement new technologies in organizations are assumed to be an important issue in technologically under resourced countries.

\section{Research hypothesis}

The following six hypotheses were formulated to test the relationship between the dependent and independent constructs of the study.

H1 Perceived usefulness positively affects behavioral intention to adopt e-learning.

H2 Perceived ease of use positively affects behavioral intention to adopt e-learning.

H3 Behavioral intention positively affects the actual usage of e-learning systems.

H4 Top management support positively affects the actual usage of e-learning systems.

H5 Training positively affects the actual usage of e-learning systems.

H6 Incentive positively affects the actual usage of e-learning systems.

\section{Materials and methods}

As the major purpose of this research was to empirically examine students' e-learning readiness, acceptance, and use in Ethiopian public universities, this study designed quantitative research methodology and employed self-administered questionnaires.

According to Kothari (2004), research design is a blueprint or a conceptual framework of the overall research process that explains and justifies the collection, measurement, and analysis of data as well as the procedures and techniques to be used in processing and analyzing data. Hence, this study mainly used a questionnaire, a survey research methodology, as a data collection instrument. A cross-sectional survey study has been employed as a quantitative research design methodology to get multiple respondents' data at a time.

The target population of the study was faculty members of five technology institutes in Ethiopia. ICT Directors of the selected universities have been interviewed to support the survey method.

Statistical package for social science (SPSS version 20) has been used for the descriptive study. Moreover, SmartPLS 3 software was used for the PLS-SEM structural model.

\section{The sampling method}

The target population consisted of 1385 teachers (Addis Ababa Institute of Technology$\mathrm{AAiT}=290$, Bahir Dar Institute of Technology-BiT $=460$, Ethiopia Institute of Textile \& Fashion Technology-EiTex $=200$, Hawasa Institute of Technology-HiT $=225$ and Jima Institute of Technology-JiT =210) from five out of the ten technology institutes in 
Ethiopia. Samples of 400 teachers were taken using simple random sampling method. The size of the sample was determined using the formula (Cochran 1977) which is appropriate for finite populations:

$$
\text { no }=\frac{(\mathrm{z} \alpha / 2)^{2} * p(1-p)}{\delta^{2}}
$$

where $N=$ total population, $n=$ required sample size, $\alpha=0.05=$ level of significant (type-I error), $\delta=0.05$ which is the margin of error, and $P=0.5$ for sample proportion of teachers:

$$
\begin{aligned}
& \text { no }=\frac{(1.96)^{2} * 0.5(1-0.5)}{(0.05)^{2}} \\
& \mathrm{no}=\frac{(3.84) * 0.5 * 0.5}{(0.0025)}=384.16 \approx 385 \\
& \mathrm{n}=\frac{\mathrm{no}}{1+\frac{\mathrm{no}}{N}} \\
& \mathrm{n}=\frac{385}{1+\frac{385}{1385}}=\frac{385}{1.278}=301.257 \approx 302 .
\end{aligned}
$$

The above formula shows that 302 samples are sufficient enough to investigate the teachers' acceptance and use of e-learning systems. Whereas, the study has used samples of 400 teachers from the five technology institutes of Ethiopian universities that can enhance the performance of the research model.

\section{Results and discussion}

\section{Socio-demographic characteristics}

Out of a total of 400 questionnaires distributed, 372 were collected indicating that the response rate was $93 \%$. From the collected 372 questionnaires, 356 (89\%) questionnaires were found usable. The rest 16 questionnaires (4\%) were rejected for the reason that either they were not properly filled or incomplete. Hence, the non-respondent rate of the main survey was $7 \%$. McColl et al. indicated that response rates greater than $50 \%$ are acceptable, $60 \%$ are good, $70 \%$ are very good, and $85 \%$ are excellent for questionnaire surveys. Hence, the $93 \%$ response rate in this study is excellent (McColl et al. 2001).

As shown in Fig. 2, the majority of respondents are from Bahir Dar Institute of Technology followed by Addis Ababa, Hawasa, Ethiopia Institute of Textile \& Fashion Technology, and Jima Institutes of Technology.

The data showed that out of 356 respondents, 283 (79.5\%), and 73 (20.5\%) were male and female, respectively. Regarding academic qualification, 82 (23\%), 230 (64.6\%), and 44 (12.4\%) of the respondents had B.Sc degree, M.Sc degree, and Ph.D. degree, respectively (Fig. 3). The data also showed that the majority of respondents (84.3\%) were young adults below 40 years old. The study also showed that colleagues and friends were the 


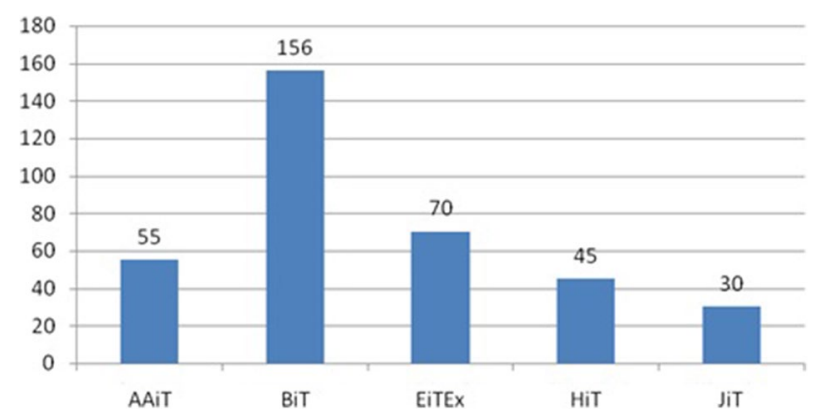

Fig. 2 Respondents per institute

Table 1 Experience * awareness level cross tabulation

\begin{tabular}{lllll}
\hline Experience & \multicolumn{2}{l}{ Level of awareness } & Total \\
\cline { 2 - 4 } & Awared & Awared to some extent & Not awared & \\
\hline Less than 5 years & 51 & 50 & 43 & $144(40.5 \%)$ \\
$6-10$ years & 74 & 46 & 10 & $130(36.5 \%)$ \\
$11-15$ years & 25 & 22 & 12 & $59(16.6 \%)$ \\
$16-20$ years & 6 & 5 & 2 & $13(3.7 \%)$ \\
More than 20 years & 6 & 4 & 0 & $10(2.8 \%)$ \\
Total & $162(45.5 \%)$ & $127(35.7 \%)$ & $67(18.8 \%)$ & $356(100 \%)$ \\
\hline
\end{tabular}

major source of awareness about e-learning (46.6\%) followed by the available facilitating conditions around (33.4\%) and the management body (28.4\%), respectively.

In this study, about $40.5 \%$ of the respondents had less than 5 years teaching experience followed by $36.5 \%$ with $6-10$ years of experience in teaching. The majority of respondents 289 (81.2\%) had the information about the existence of e-learning systems in their institute. The 162 respondents (45.5\%) were well informed and 127 respondents (35.7\%) had some awareness about the existence of e-learning systems. The rest 67 respondents (18.8\%) were not informed at all about the existence and importance of e-learning systems in their Institute, as shown in Table 1.

\section{E-learning acceptance and use in technology institutes of Ethiopian Public Universities}

Using partial least square structural equation modeling (PLS-SEM) technique, the determinants of e-learning acceptance and use in technology institutes of Ethiopian universities have been identified. Perceived ease of use and perceived usefulness were considered to have an impact on the behavioral intention of teachers to use e-learning systems. Organizational parameters like management support, incentive, and user training were incorporated with the original TAM model constructs to describe actual usage.

Cronbach's Alpha coefficient and composite reliability measures of each construct were greater than the minimum threshold value 0.60 (Chin 1998). As indicated in Table 2, the reliability of the main constructs of the structural model showed strong consistency of the responses (perceived usefulness $=0.94$, perceived ease of use $=0.83$, organizational factor $=0.82$, behavioral intention $=0.90$, and actual usage $=0.91$ ). The 


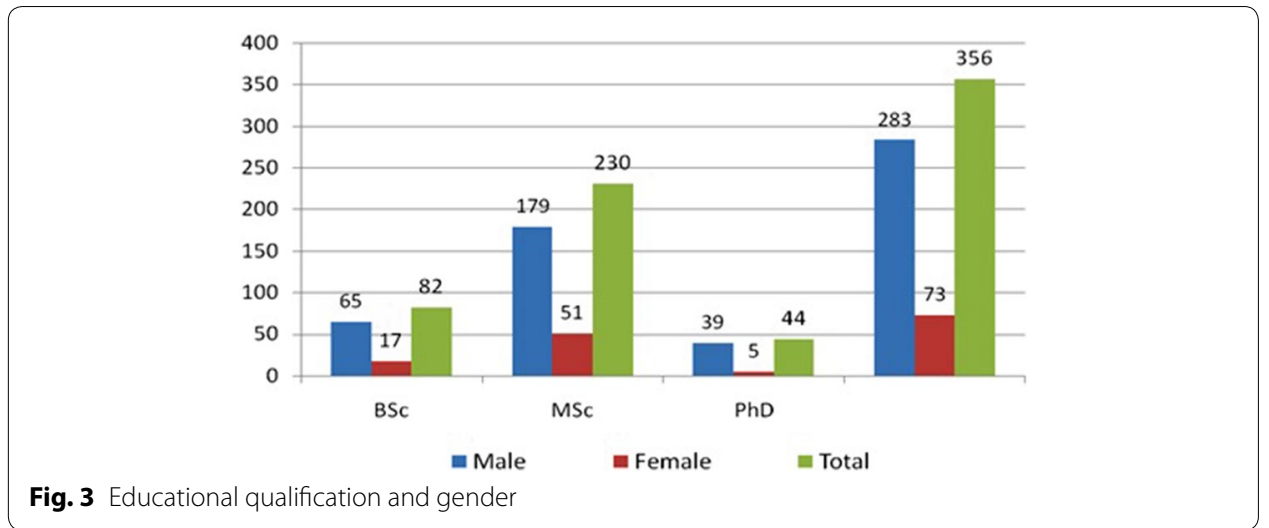

Table 2 Construct reliability and validity

\begin{tabular}{lllll}
\hline Constructs & Number of items & Cronbach's Alpha & Composite reliability & $\begin{array}{l}\text { Average variance } \\
\text { extracted (AVE) }\end{array}$ \\
\hline $\begin{array}{l}\text { Perceived usefulness } \\
\text { (PU) }\end{array}$ & 7 & 0.94 & 0.95 & 0.74 \\
$\begin{array}{c}\text { Perceived ease of use } \\
\quad \text { PEOU) }\end{array}$ & 4 & 0.83 & 0.89 & 0.68 \\
$\begin{array}{l}\text { Organizational factor } \\
\text { (OF) }\end{array}$ & 15 & 0.82 & - & - \\
$\begin{array}{l}\text { Management sup- } \\
\text { port (MS) }\end{array}$ & 8 & 0.96 & 0.96 & 0.76 \\
$\begin{array}{l}\text { Incentives (INC) } \\
\text { Training (TRA) }\end{array}$ & 4 & 0.83 & 0.89 & 0.66 \\
$\begin{array}{l}\text { Behavioral intention } \\
\text { (BI) }\end{array}$ & 3 & 0.38 & 0.66 & 0.43 \\
$\begin{array}{l}\text { Actual usage (AU) } \\
\text { Overall }\end{array}$ & 4 & 0.90 & 0.94 & 0.83 \\
\hline
\end{tabular}

overall reliability of the instrument on the 33 indicators (0.87) has also depicted a strong consistency of the responses.

The average variance extracted (AVE) measures the average communality of latent variables and tests convergent and divergent validity. The average variance extracted (AVE) values except for the training construct were greater than the cutoff $(0.50)$ for all constructs which ensured the adequacy of the model (Hu and Bentler 1998).

\section{Fornell-Larcker criterion}

The Fornell-Larcker measures discriminant validity of the latent variable. For any latent variable, the square root of AVE that appears in diagonal cells should be higher than its correlation with any other latent variable. The top numbers in any of the factor columns were higher than correlations below it indicating that the model was good, as shown in Table 3.

Heterotrait-monotrait ratio (HTMT)

Another method of measuring discriminant validity is heterotrait-monotrait ratio (HTMT). Heterotrait correlations should be smaller than monotrait correlations in 
Table 3 Fornell-Larcker criterion

\begin{tabular}{llllllll}
\hline & AU & BI & INC & PEOU & PU & TMS & TRA \\
\hline AU & 0.883 & & & & & & \\
BI & 0.231 & 0.910 & & & & \\
INC & 0.103 & 0.109 & 0.815 & & & \\
PEOU & 0.527 & 0.360 & 0.051 & 0.825 & & \\
PU & 0.158 & 0.373 & 0.040 & 0.397 & 0.859 & & \\
TMS & 0.351 & 0.019 & 0.275 & 0.270 & 0.089 & 0.873 & \\
TRA & 0.339 & 0.169 & 0.328 & 0.301 & 0.134 & 0.248 & 0.656 \\
\hline
\end{tabular}

Table 4 Heterotrait-monotrait ratio (HTMT)

\begin{tabular}{lllllll}
\hline & AU & BI & INC & PEOU & PU & TMS \\
\hline BI & 0.252 & & & & & \\
IINC & 0.117 & 0.117 & & & & \\
PEOU & 0.580 & 0.388 & 0.068 & & & \\
PU & 0.168 & 0.397 & 0.104 & 0.431 & & \\
TMS & 0.367 & 0.063 & 0.304 & 0.282 & 0.098 & \\
TRA & 0.459 & 0.472 & 0.537 & 0.496 & 0.297 & 0.358 \\
\hline
\end{tabular}

Table 5 Standardized root mean square residual (SRMR)

\begin{tabular}{llc}
\hline SRMR & $\boldsymbol{T}$ statistics & $P$ values \\
\hline 0.070 & 8.142 & 0.000 \\
\hline
\end{tabular}

well-fitted model. Since HTMT ratios were below the cutoffs (0.85), the values in Table 4 ensured discriminant validity (Clark and Watson 1995).

\section{Standardized root mean square residual (SRMR)}

Standardized root mean square residual determines the difference between the observed correlation matrix and the model-implied correlation matrix by measuring the approximate fit of a research model. A model has good fit when SRMR is less than $0.08(\mathrm{Hu}$ and Bentler 1998). For this study, SRMR value of 0.07 was below the cutoff (0.08). The $T$ statistics value greater than 1.96 and $P$ value less than 0.05 indicated that SRMR was significant, as indicated in Table 5 .

\section{The path coefficients and model goodness of fit}

The coefficient of determination, $r$ square, is the overall effect size measure for the structural model. Chin (1998) explained the $r$ square values greater than the cutoffs $0.67,0.33$, and 0.19 to be substantial, moderate, and weak, respectively. Despite the study model seemed to be under the third category (0.23), the $T$ statistic values greater than 1.96 and $P$ values less than 0.05 for $r$ square indicated that the model was significant, as indicated in Table 6. 
Table 6 R-square

\begin{tabular}{llll}
\hline & $\boldsymbol{R}$ square & $\boldsymbol{T}$ statistics & $\boldsymbol{P}$ values \\
\hline Actual usage & 0.230 & 5.787 & 0.000 \\
Behavioral intention & 0.192 & 5.085 & 0.000 \\
\hline
\end{tabular}

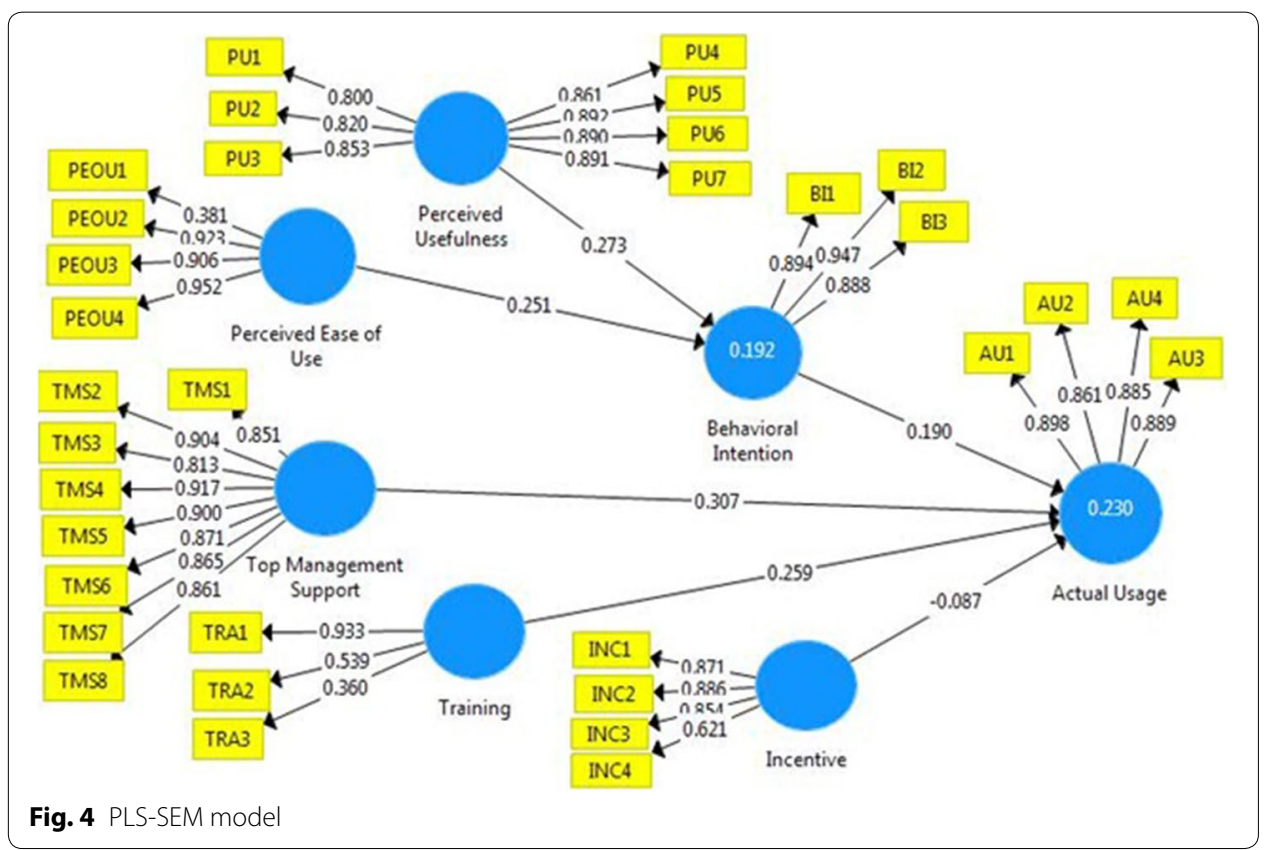

Table 7 Path coefficients

\begin{tabular}{lccc}
\hline & Path coefficient & T statistics & $P$ values \\
\hline Behavioral intention $\rightarrow$ actual usage & 0.190 & 4.833 & 0.000 \\
Incentive $\rightarrow$ actual usage & -0.087 & 1.202 & 0.230 \\
Perceived ease of use $\rightarrow$ behavioral intention & 0.251 & 5.482 & 0.000 \\
Perceived usefulness $\rightarrow$ behavioral intention & 0.273 & 4.417 & 0.000 \\
Top management support $\rightarrow$ actual usage & 0.307 & 5.833 & 0.000 \\
Training $\rightarrow$ actual usage & 0.259 & 4.963 & 0.000 \\
\hline
\end{tabular}

The path coefficients of the constructs were found to be the core determinants of behavioral intention and actual usage of e-learning systems. The independent constructs have depicted different contributions to the dependent construct, as presented in Fig. 4 and Table 7.

Perceived usefulness and perceived ease of use were determinants of behavioral intention. Behavioral intention, management support, and training were significant determinants of actual usage. However, incentive has no contribution for actual usage. The $T$ statistics below the cutoff (1.96) and the $P$ value above 0.05 indicated that incentive was not a significant factor. The $T$ statistics and the $P$ values for all path coefficients except incentive were significant. 
Perceived usefulness contributed positively towards behavioral intentions to use e-learning systems. The positive path coefficient of ( 0.273 coefficient $)$ described that e-learning system end-users' inclination to use the services was due to the perceived usefulness construct. This implied that perceived usefulness accounted $27.3 \%$ contribution alone to behavioral intention. Perceived usefulness was found among the determinants of behavioral intention to use e-learning systems. Therefore, the hypothesis was accepted.

Perceived ease of use contributed positively towards behavioral intentions to use e-learning systems. The positive path coefficient of 0.251 explained that e-learning system end-users' inclination to use the services were due to the perceived ease of use construct which accounted $25.1 \%$ contribution alone to behavioral intention. This implied that perceived ease of use was among the determinants of behavioral intention to use e-learning systems. Therefore, the hypothesis was accepted.

Behavioral intention positively contributes an effect towards usage behavior of e-learning systems. A positive path coefficient of (0.190) indicated that the behavioral intention construct had $19 \%$ contribution to the actual usage behaviors of e-learning systems. This implies that behavioral intention was among the determinants of e-learning usage. Therefore, the hypothesis was accepted.

Top management support positively contributed an effect towards usage behavior of e-learning systems. A positive path coefficient of (0.307) indicated that management support latent variable or construct had $30.7 \%$ contribution to the actual usage behaviors of e-learning systems. This implies that management support was the major determinant of e-learning usage. Therefore, the hypothesis was accepted.

Training positively contributed an effect towards usage behavior of e-learning systems. A positive path coefficient of 0.259 indicated that the training construct had $25.9 \%$ contribution to the actual usage behaviors of e-learning systems. This implied that training was among the determinants of e-learning implementation and usage. Therefore, the hypothesis was accepted.

Incentive negatively contributed an effect towards usage behavior of e-learning systems. A negative path coefficient of -0.087 indicated that the incentive latent variable had $-8.7 \%$ contribution to the actual usage behaviors of e-learning systems. This implied that incentive was not a determinant of e-learning implementation and usage. Therefore, the hypothesis was rejected.

\section{Conclusions}

Evaluating the acceptance and use of e-learning systems in universities must be in place to ensure its implementation success. Therefore, identifying the major determinant factors of intention to use and actual usage behaviors is the first step to utilize the systems efficiently and effectively. The TAM model constructs (perceived ease of use and perceived usefulness) were considered to have an impact on the behavioral intention of teachers to use e-learning. The result indicated that perceived ease of use $(25.1 \%)$ and perceived usefulness (27.3\%) have demonstrated significant contributions to behavioral intention of teachers to use e-learning. Moreover, behavioral intention (19\%) has also shown a significant contribution for the actual usage of e-learning systems. 
Organizational parameters like management support, incentive, and user training were incorporated with the original TAM model to describe the actual usage of e-learning systems among teachers. The result indicated that top management support and training constructs jointly contributed $56.6 \%$ of e-learning usage. Likewise, management support was the most significant determinant factor (highest positive contributor, 30.7\%) in explaining users' actual usage behavior. Yet, among the organizational factors, incentive has shown a weak and negative contribution to the actual usage of e-learning systems.

\section{Recommendation}

Based on the data obtained from the questionnaire responses, the following recommendations are forwarded to improve the use of e-learning systems in Ethiopian Universities and for future works.

The first recommendations are suggestions for the management body of universities' at different levels of administration. Therefore, presidents, scientific directors, deans, and department heads should:

- Improve the awareness of staff on the usage of e-learning systems;

- Encourage teachers to incorporate e-learning usage plan in course guide book;

- Encourage their staff to build good culture of new technology usage in general.

The second recommendation is for further research. This study has considered only teachers in the five technology institutes and used 400 respondents. Therefore, there are numerous reasons to pursue further research extending the study in all universities and disciplines and considering more sample size. In addition to teachers, incorporating students of higher education in the study applying other models like the UTAUT as well as methods like PLS-SEM and CB-SEM may be other perspectives to be studied.

Authors' contributions

The corresponding author, AAA, worked from initiation to lose out of the research work. The co-author, WKB, also included his valuable contribution to this research particularly by providing valuable comments on the overall research write up. Both authors read and approved the final manuscript.

Authors' information

Abinew Ali Ayele has studied his B.Sc in Information Technology and M.Sc in Information Science at Addis Ababab University. He is currently working as a lecturer in the faculty of Computing, Bahir Dar Institute of Technology, Bahir Dar University and as e-service research group head and researcher at ICT4D research centre, Bahir Dar University. Worku Kelemework Birhanie has studied his B.Sc in Information Technology and M.Sc in Information Science at Addis Ababab University. He is currently working as a lecturer in the faculty of Computing, Bahir Dar Institute of Technology, Bahir Dar University and as a researcher at ICT4D research centre, Bahir Dar University.

\section{Acknowledgements}

Our first respected gratitude goes to Bahir Dar University, Bahir Dar Institute of Technology, School of research and Graduate studies for funding this research with their ambitious plan of encouraging research to be engaged in scientific investigations. Second, our gratitude goes to those research participants who devoted their valuable time and effort and contributed their valuable experiences to this study. Finally, we would like to dedicate this research work to our families for their love, encouragement, patience, and unconditional support.

\section{Competing interests}

We confirm that this research is an original work and there is no any individual or organization having competing interest on this study.

Availability of data and materials

The Survey results of those 262 respondents are available in Excel and SPSS V.20 software.

\section{Consent for publication}

We, authors, agree the publication of this research work. 
Ethics approval and consent to participate

The participants have shown their willingness in the survey process. In the study, ethical issues such as confidentiality of personal information of the participants are kept confidential.

\section{Funding}

This research has been done with a grant support received from Bahir Dar University, Bahir Dar Institute of Technology, School of research and Graduate studies from August 2016 to October 2017.

\section{Publisher's Note}

Springer Nature remains neutral with regard to jurisdictional claims in published maps and institutional affiliations.

Received: 20 January 2018 Accepted: 11 May 2018

Published online: 24 May 2018

\section{References}

Ajzen I, Fishbein M (1980) Understanding attitudes and predicting social behavior. Prentice-Hall, New Jersey

Al Haderi SM (2014) The influences of government support in accepting the information technology in public organization culture. Int J Bus Soc Sci 5(5):118-124

Alharbi S, Drew S (2014) Using the technology acceptance model in understanding academics' behavioural intention to use learning management systems. Int J Adv Comput Sci Appl 5(1):143-155

Al-Mamary YH, Shamsuddin A, Abdul Hamid NA (2014) Key factors enhancing acceptance of management information systems in Yemeni companies. J Bus Manag Res 5(1):108-111

Arkorful V, Abaidoo N (2015) The role of e-learning, advantages and disadvantages of its adoption in higher education. Int J Instr Technol Distance Learn 12(1):29-42

Chin WW (1998) The partial least squares approach to structural equation modeling. Mod Methods Bus Res 295(2):295-336

Clark LA, Watson D (1995) Constructing validity: basic issues in objective scale development. Psychol Assess 7(3):309

Cochran WG (1977) Sampling techniques. Wiley, Hoboken

Davis FD (1989) Perceived usefulness, perceived ease of use, and user acceptance of information technology. MIS Q 13:319-340

Ethiopian Ministry of Education (2015) The second growth and Transformation plan for the Higher Education Sector Ethiopian Ministry of Education, Addis Ababa

European Commission (2001) The eLearning Action Plan: Designing tomorrow's education. http://www.elearningeuropa. info

Hu LT, Bentler PM (1998) Fit indices in covariance structure modeling: sensitivity to underparameterized model misspecification. Psychol Methods 3(4):424

Kothari CR (2004) Research methodology: methods and techniques. New Age International, New Delhi

Maina MK, Nzuki DM (2015) Adoption determinants of e-learning management system in institutions of higher learning in Kenya: a case of selected universities in Nairobi Metropolitan. Int J Bus Soc Sci 6(2):223-248

Mbengo P (2014) E-learning adoption by lecturers in selected Zimbabwe State Universities: an application of technology acceptance model. J Bus Adm Educ 6(1):15-33

McColl E, Jacoby A, Thomas L, Soutter J, Bamford C, Steen N, Thomas R, Harvey E, Garratt A, Bond J (2001) Design and use of questionnaires: a review of best practice applicable to surveys of health service staff and patients. Health Technol Assess 5(31):1-256

Talukder M, Quazi A (2010) Exploring the factors affecting employees'adoption and use of innovation. Australas J Inf Syst 16(2):1-30

\section{Submit your manuscript to a SpringerOpen ${ }^{\circ}$ journal and benefit from:}

- Convenient online submission

- Rigorous peer review

- Open access: articles freely available online

- High visibility within the field

- Retaining the copyright to your article

Submit your next manuscript at $\boldsymbol{\nabla}$ springeropen.com 